\title{
Correlation among the Changes in Mechanical Properties due to Neutron Irradiation for Pressure Vessel Steels
}

\author{
Kunio ONIZAWA and Masahide SUZUKI
}

Department of Reactor Safety Research, Tokai Research Establishment, Japan Atomic Energy Research Institute, Tokai-mura, Ibaraki-ken, 319-11 Japan.

(Received on March 7, 1997; accepted in final form on April 11, 1997)

\begin{abstract}
Irradiation hardening and embrittlement of reactor pressure vessel (RPV) steels having different contents of copper and nickel have been investigated as a part of the phase III of IAEA Coordinated Research Program (CRP). Seven kinds of materials which were made by Japanese steel manufacturers for the CRP were used. Neutron irradiation was conducted in Japan Materials Testing Reactor (JMTR). Mechanical properties of the materials were examined by conducting the hardness, tensile, Charpy impact and fracture toughness tests before and after irradiation. Some relationships between the changes of the mechanical properties due to irradiation were established. The increase in yield strength was correlated with hardness increase and the shift of Charpy transition temperature. In the upper shelf temperature range, the decrease in fracture toughness was well correlated with the degree of the increase in yield strength.
\end{abstract}

KEY WORDS: pressure vessel steel; neutron; irradiation embrittlement; chemical composition; mechanical property; transition temperature; fracture toughness; Charpy impact test; structural integrity; surveillance.

\section{Introduction}

The life time of nuclear power plant is greatly dependent on the operational life of major components that are difficult to repair and replace. The reactor pressure vessel (RPV) is one of the important components that the integrity should be maintained at highest degree to continue safe operation. To assess the integrity of an RPV, material degradation due to aging, in particular, neutron irradiation embrittlement of the steel should be evaluated quantitatively and precisely. In this respect, the prediction and the evaluation of mechanical properties, such as Charpy impact property and fracture toughness of the steels are very important.

Extensive studies on irradiation embrittlement of RPV steels have been performed since nuclear reactor was commenced to operate. The IAEA Coordinated Research Program (CRP) on irradiation embrittlement of pressure vessel steels was initiated in 1971, and the phase II and the phase III of CRP were continued afterwards. ${ }^{1-3)}$ The phase III of CRP, entitled "Optimizing of Reactor Pressure Vessel Surveillance Programmes and their Analysis," was initiated in 1983. Fifteen countries participated in the phase III program. The Japan Atomic Energy Research Institute (JAERI) took part in the program and performed the experiments on irradiation embrittlement of RPV steels. The results of the experiments performed at JAERI have been described elsewhere. ${ }^{4)}$

The mechanical tests of irradiated specimens are usually limited to a small number of the iteration. To determine the proper testing conditions, it is desirable to predict the mechanical property before the test by means of correlation between the other property. The correlation also helps to obtain more reliable results. Several predictive equations for the shift of Charpy transition temperature have been developed based on the analyses of surveillance test results, e.g. Ref. 5). These equations were formulated based primarily on chemical composition of steels and fast neutron fluence values. However, the prediction formula for fracture toughness change has not yet been established. On the other hand, the microstructural studies on radiation damage of RPV steels have been performed mainly for the irradiation hardening, e.g. Ref. 6). Therefore, the correlation between the irradiation hardening and the changes of different mechanical properties, in particular, fracture toughness should be established.

The chemical composition of RPV steels has changed with the improvement of the technology for manufacturing steels. The impurity elements in steel have been decreased gradually since the first generation of nuclear power plants was constructed. Hence RPV steels of the nuclear power plants which are now being operated have some variations in the level of impurity elements. The objective of this study is to investigate the correlation between different mechanical properties of irradiated materials having a certain range of alloying and impurity elements that cover the range of chemical composition for the Japanese PWR pressure vessel steels. 


\section{Experimental Procedure}

\subsection{Materials}

Chemical compositions of the steels used are shown in Table 1. These materials designated as JPD, JPF, JPH, JPI, JPJ, JFL and JRQ were made by Japanese steel manufacturers for the phase III of IAEA CRP. ${ }^{7}$ All materials were made as ASTM A533B class 1 plates, except for the JFL which was ASTM A508 class 3 forging. The materials have a wide range of chemical composition on the elements, copper, nickel and phosphorus, which are very important from the viewpoint of irradiation embrittlement of RPV steels. Figures 1(a) and 1(b) shows the compositional range of materials used in this

Table 1. Chemical composition of materials used in the present study. (wt\%)

\begin{tabular}{|c|c|c|c|c|c|c|c|c|c|c|c|c|c|}
\hline $\begin{array}{c}\text { Element } \\
\text { Material }\end{array}$ & $\mathrm{C}$ & $\mathrm{Si}$ & $\mathrm{Mn}$ & $\mathrm{P}$ & $\mathrm{S}$ & $\mathrm{Cu}$ & $\mathrm{Ni}$ & $\mathrm{Cr}$ & $\mathrm{Mo}$ & $\mathrm{V}$ & $\mathrm{Al}$ & $\mathrm{Spec}$. & $\begin{array}{c}\text { Thick } \\
\text { ness } \\
(\mathrm{mm})\end{array}$ \\
\hline $\mathrm{JPD}$ & 0.19 & 0.27 & 1.45 & 0.006 & 0.001 & 0.16 & 0.10 & 0.15 & 0.55 & 0.01 & 0.019 & A533B1-Ni & 30 \\
\hline $\mathrm{JPF}$ & 0.18 & 0.27 & 1.49 & 0.020 & 0.001 & 0.16 & 0.62 & 0.15 & 0.55 & 0.01 & 0.010 & A533B1 & 30 \\
\hline $\mathrm{JPH}$ & 0.18 & 0.27 & 1.45 & 0.006 & 0.001 & 0.17 & 1.18 & 0.15 & 0.54 & 0.01 & 0.021 & A533B1+Ni & 30 \\
\hline $\mathrm{JPI}$ & 0.18 & 0.21 & 1.50 & 0.006 & 0.001 & 0.01 & 0.69 & 0.17 & 0.57 & 0.001 & 0.012 & $\mathrm{~A} 533 \mathrm{~B} 1$ & 163 \\
\hline $\mathrm{JPJ}$ & 0.18 & 0.21 & 1.41 & 0.005 & 0.001 & 0.05 & 0.64 & 0.10 & 0.50 & $<0.003$ & - & A533B1 & 250 \\
\hline JFL & 0.17 & 0.25 & 1.44 & 0.004 & 0.002 & 0.01 & 0.75 & 0.20 & 0.51 & 0.004 & 0.016 & A508-3 & 290 \\
\hline JRQ & 0.18 & 0.24 & 1.42 & 0.017 & 0.004 & 0.14 & 0.84 & 0.12 & 0.51 & 0.002 & 0.014 & A533B & 225 \\
\hline
\end{tabular}
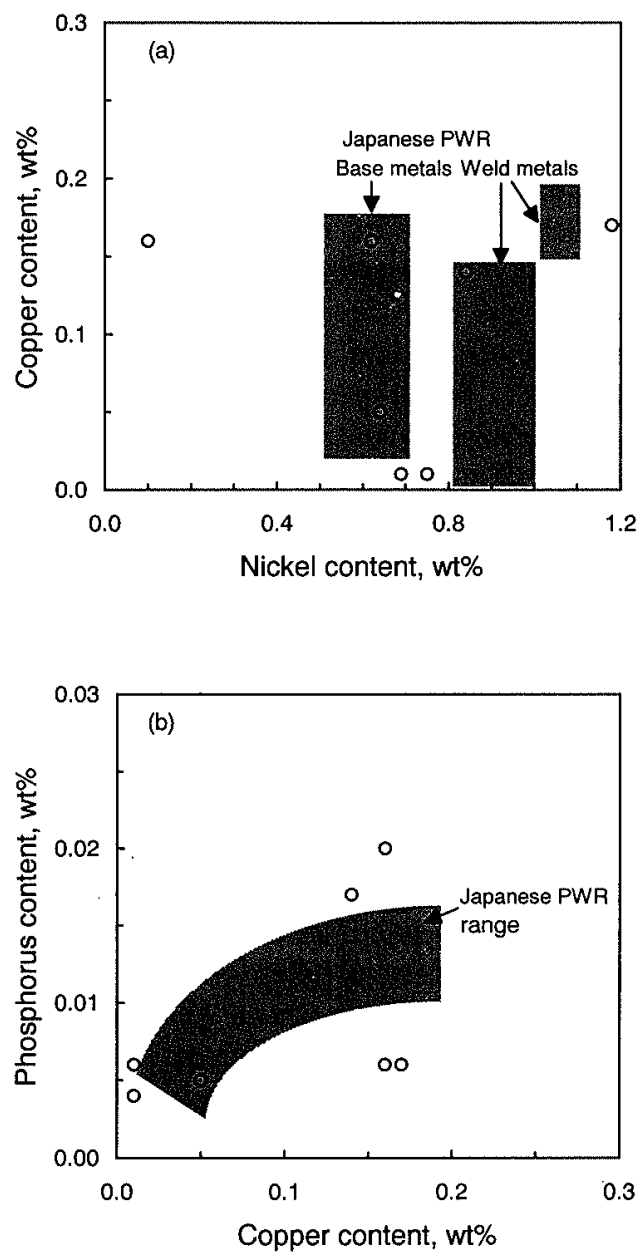

Fig. 1. Copper vs. nickel (a) and phosphorus vs. copper (b) contents in steels used in the present study. Estimated ranges of the Japanese PWR steels are also drawn as hatched regions. study together with that of Japanese PWR pressure vessel steels. Three kinds of laboratory melted alloys (JPD, JPF and JPH) were manufactured in $30 \mathrm{~mm}$ thickness. The other heavy section steels were with thickness from 163 to $290 \mathrm{~mm}$. Heat treatments of these steels are summarized in Table 2. For the heavy section steels (JPI, JPJ, JFL and JRQ), the specimens for the mechanical tests were machined from the quarter thickness position of materials. The cooling rate at quenching for the laboratory melted materials was controlled to be almost same as the rate at the quarter thickness position of the heavy section steels. Post weld heat treatment (T2) was applied to the heavy section steels. Microstructures of materials are almost identical, i.e., bainitic structure with a small amount of ferrite.

\subsection{Neutron Irradiation}

Test specimens from materials mentioned above were irradiated in the Japan Materials Testing Reactor (JMTR, thermal output $50 \mathrm{MW}$ ). The irradiation was performed by using eight capsules that contained electric heaters, thermocouples and fluence monitors. All capsules were irradiated at the same irradiation hole in the second Beryllium reflector region of JMTR core. The average values of neutron fluence in the seven capsules were $\sim 2 \times 10^{19} \mathrm{n} / \mathrm{cm}^{2}(E>1 \mathrm{MeV})$, whereas the fluence for one capsule was $\sim 4 \times 10^{19} \mathrm{n} / \mathrm{cm}^{2}(E>1 \mathrm{MeV})$. The fluence value at each specimen position was evaluated by the values obtained from four fluence monitors in the capsule and the database of the fluence values determined by past experiments at the same irradiation hole. The ratio of neutron fluence with energy greater than $0.1 \mathrm{MeV}$ to that for $1 \mathrm{MeV}$ was approximately 2.6. Displacement per atom (dpa) for iron by the irradiation to $2 \times 10^{19} \mathrm{n} / \mathrm{cm}^{2}(E>1 \mathrm{MeV})$ was about 0.031 . The fast neutron flux was approximately $1 \times 10^{13} \mathrm{n} / \mathrm{cm}^{2} \mathrm{~s}(E>$ $1 \mathrm{MeV}$ ) for all capsules. The temperature of specimens during irradiation was controlled in the range from 280 to $300^{\circ} \mathrm{C}$ for all capsules.

\subsection{Charpy Impact, Tensile and Hardness Tests}

Charpy impact tests were performed using a test machine with the capacity of $300 \mathrm{~J}$ installed in a hot cell. The machine was designed according to JIS B7722 (Japan Industrial Standard B7722, similar to the related ISO standard). The configuration and dimensions of the specimen are shown in Fig. 2(a) which are also in

Table 2. Heat treatment condition of materials used in the present study.

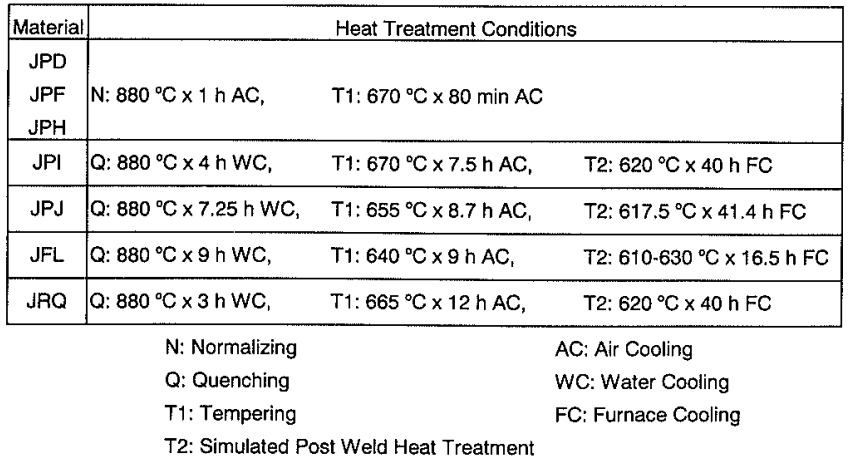




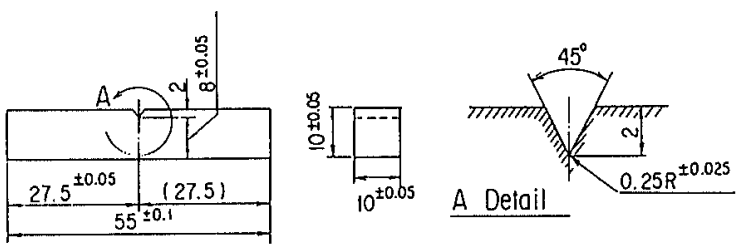

(a) Charpy V-notch specimen

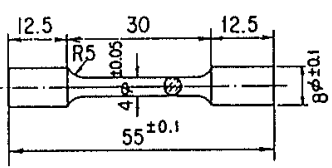

(b) Tensile specimen
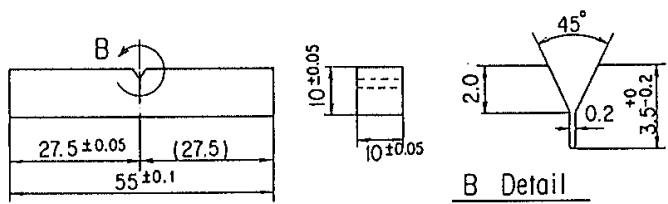

(c) Precracked Charpy (PCCv) specimen

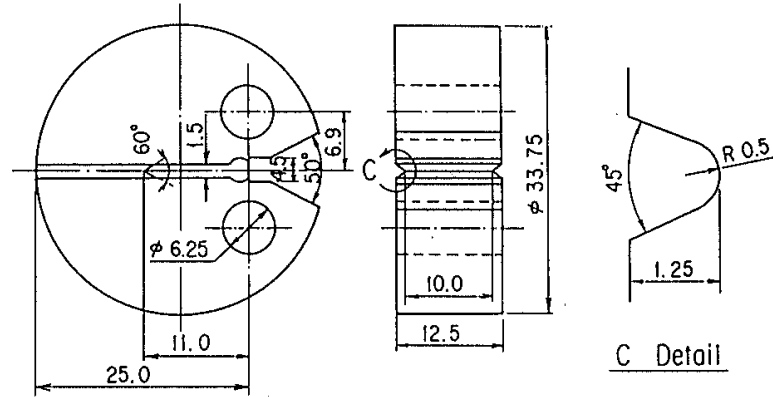

(d) 0.5T-DCT specimen
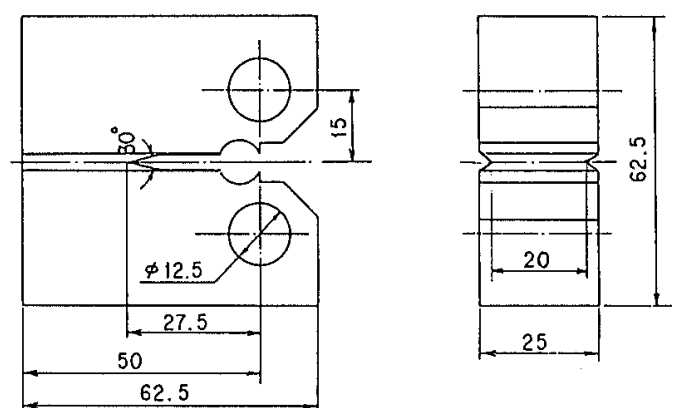

(e) 1T-CT specimen

Fig. 2. Configurations and dimensions of test specimens.

accordance with JIS Z2202. The notch orientation of the specimen is T-L direction according to ASTM E399. ${ }^{8)}$

Charpy transition curves were determined by fitting all data to the following hyperbolic tangent equation. ${ }^{9)}$

$$
\mathrm{CVN}=A+B \times \tanh \{(T-T o) / C\}
$$

where CVN: Charpy absorbed energy,

$T$ : Test temperature,

$A, B, C, T o$ : Fitting constants.

Charpy upper shelf energy (USE) was determined as the average of all absorbed energy values that exhibited fully ductile tearing on the fracture surface.

Tensile tests were conducted using an electromechanical servo type test machine with the capacity of $100 \mathrm{kN}$. The tensile specimen has dimensions of $4 \mathrm{~mm}$ in diameter and $22 \mathrm{~mm}$ in gauge length (see Fig. 2(b)). The tensile direction of the specimen was perpendicular to the major working direction of materials. The yield strength of the materials was determined from the load at lower yield point. Vickers hardness tests were done using a half of broken Charpy specimen with an applied load of $98 \mathrm{~N}$.

\subsection{Fracture Toughness Tests}

To measure fracture toughness, two types of specimen were used. One was a precracked Charpy-V type (PCCV) specimen (see Fig. 2(c)), and another was a compact type specimen $(12.5 \mathrm{~mm}$ thick disk-shaped compact, $0.5 \mathrm{~T}$ DCT (Fig. 2(d)), and $25 \mathrm{~mm}$ thick standard compact, 1T-CT (Fig 2(e)). 1T-CT specimens were tested only in the unirradiated condition. Crack plane orientation of all fracture toughness test specimens was $\mathrm{T}-\mathrm{L}$ direction. Fracture toughness testing was performed based on ASTM E813 method. ${ }^{10)}$ Precracking into specimens was performed before irradiation using fatigue load of $10 \mathrm{~Hz}$ sinusoidal wave in air. Maximum stress intensity factor during precracking was kept less than $30 \mathrm{MPa} \mathrm{m}^{0.5}$. The ratio of initial crack length to specimen width is 0.55 to 0.6 . After precracking, side groove of $10 \%$ of thickness was machined in each side for compact type specimen.

In the ductile-brittle fracture transition temperature range, fracture toughness based on J-integral value was determined by the onset of cleavage fracture that corresponded to the sudden load drop. The fracture toughness $\left(K_{\mathrm{JC}}\right)$ value was converted from the $\mathrm{J}$-integral value at the cleavage fracture point.

The unloading compliance method according to ASTM E813 was applied to establish a J-integral resistance $(J-\Delta a)$ curve using a single specimen method at upper shelf test temperature. The multiple specimen technique according to ASTM E813 was also used for making a $J-\Delta a$ curve in some conditions.

\section{Results and Discussion}

\subsection{Increase in Yield Strength Caused by Neutron Ir- radiation}

As is known well, $\mathrm{Cu}$ and $\mathrm{Ni}$ affect greatly the irradiation hardening and embrittlement. Increase in yield strength $\left(\sigma_{y}\right)$ is caused by irradiation and is usually considered as a basic information on irradiation hardening. Figure 3 shows the increase in $\sigma_{y}$ at room temperature 


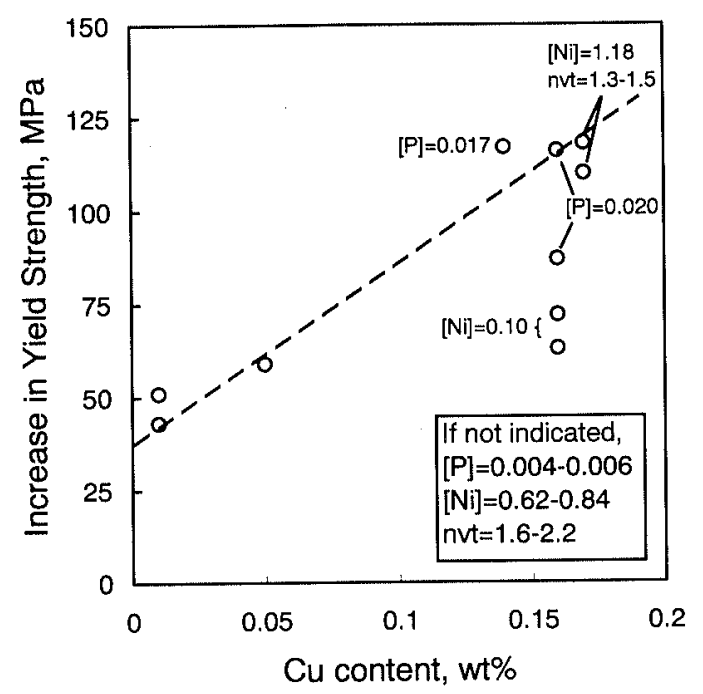

Fig. 3. Increase in yield strength caused by irradiation as a function of copper content in steels. [P], [Ni]: wt \%, nvt: $\times 10^{19} \mathrm{n} / \mathrm{cm}^{2}, E>1 \mathrm{MeV}$

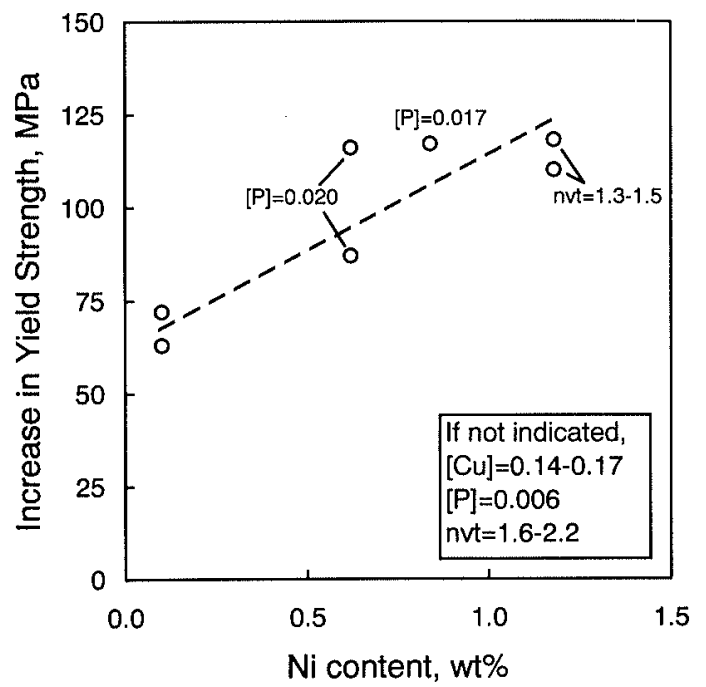

Fig. 4. Increase in yield strength caused by irradiation as a function of nickel content in steels. [Cu], [P]: wt \%, nvt: $\times 10^{19} \mathrm{n} / \mathrm{cm}^{2}, E>1 \mathrm{MeV}$

caused by irradiation as a function of $\mathrm{Cu}$ content. It is clear that the increase in $\sigma_{y}$, that is, the irradiation hardening became larger with increasing $\mathrm{Cu}$ content, although there are some variations in nickel and phosphorus contents and neutron fluence (nvt) as indicated in the figure. For materials with high $\mathrm{Cu}$ content (0.16$0.17 \mathrm{wt} \% \mathrm{Cu}$ ), the $\sigma_{\mathrm{y}}$ increase tends to be affected also by $\mathrm{Ni}$ contents. This fact is more clearly seen in Fig. 4, where the $\sigma_{\mathrm{y}}$ increase is plotted as a function of $\mathrm{Ni}$ content. The irradiation hardening increases with increasing $\mathrm{Ni}$ content from 0.1 to $1.18 \mathrm{wt} \%$. The trend of nickel dependence is consistent with the data in Ref. 11). Thus the irradiation hardening is used as a basic information for evaluating correlations between mechanical properties in this paper.

\subsection{Relationship of Changes of Hardness and Charpy Impact Properties with Increase in Yield Strength}

Figure 5 shows the correlation between the increases in $\sigma_{\mathrm{y}}$ and Vickers hardness $\left(H_{\mathrm{V}}\right)$ measured at room

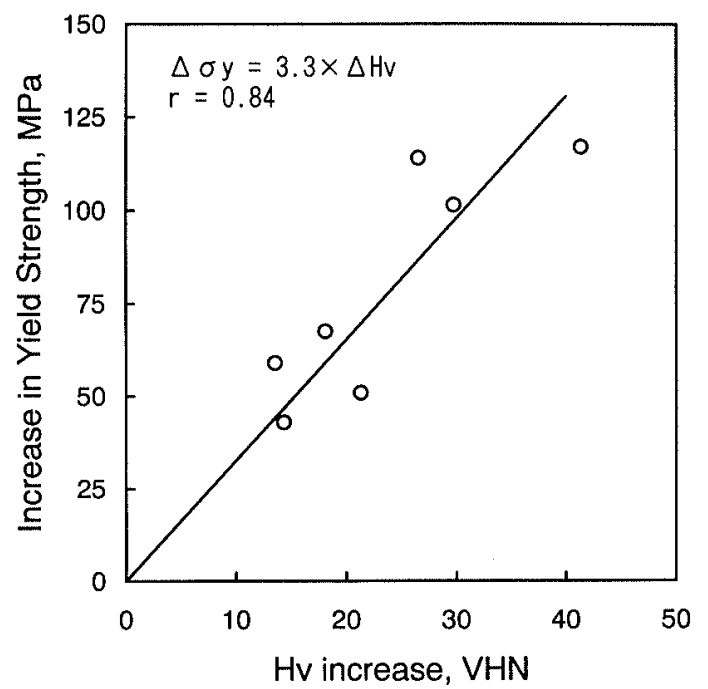

Fig. 5. Correlation between the increases in yield strength and Vickers hardness by irradiation.

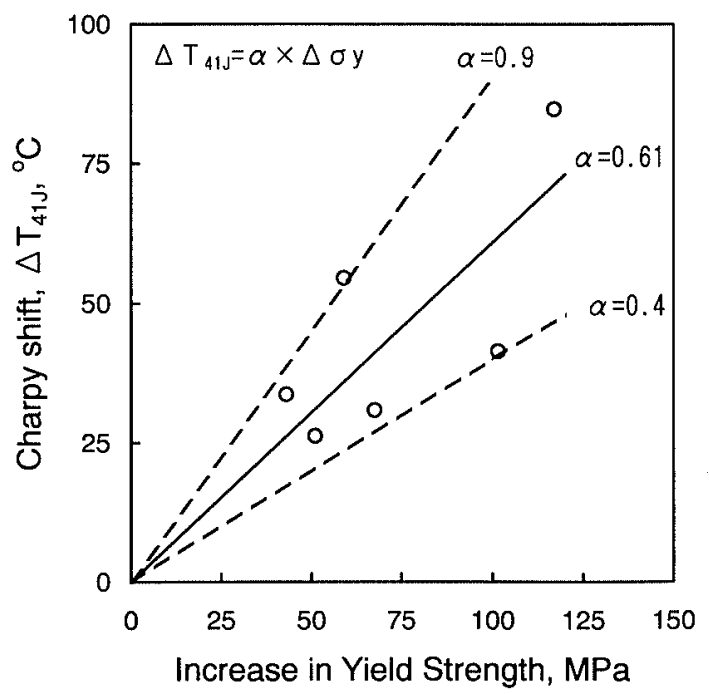

Fig. 6. Correlation between Charpy $41 \mathrm{~J}$ shift and yield strength increase by irradiation. The average $\alpha$ is $0.61\left({ }^{\circ} \mathrm{C} / \mathrm{MPa}\right)$.

temperature. The regression line is expressed by the following relation.

$$
\Delta \sigma_{\mathrm{y}}=3.3 \times \Delta H_{\mathrm{v}}
$$

where $\Delta \sigma_{\mathrm{y}}$ : increase in yield strength by irradiation, $\Delta H_{\mathrm{V}}$ : increase in Vickers hardness by irradiation correlation factor, $r=0.84$.

This correlation means that the increase in $\sigma_{y}$ caused by irradiation can be estimated from hardness values for materials used in this study. It can be applied to the RPV steels in the Japanese PWR.

For Charpy impact properties, a ductile-to-brittle transition temperature and an USE value are important as measures of irradiation embrittlement. Figure 6 shows the relationship between the shift of Charpy transition temperature at $41 \mathrm{~J}$ absorbed energy level, $\Delta T_{41 \mathrm{~J}}$, and $\sigma_{\mathrm{y}}$ increase at room temperature. The $\Delta T_{41 \mathrm{~J}}$ of JPH was not obtained because of large scatter in the data around $41 \mathrm{~J}$ level. The relation is usually expressed by the linear equation as follows, 


$$
\Delta T_{41 \mathrm{~J}}=\alpha \times \Delta \sigma_{\mathrm{y}}
$$

$\alpha:$ coefficient, the average value $=0.61\left({ }^{\circ} \mathrm{C} / \mathrm{MPa}\right)$

The average value of $\alpha$ obtained in this study agrees well with Ref. 12), although $\alpha$ has a relatively large scatter from 0.4 to 0.9 . Specimens from laboratory melts (JPD and JPF) and a steel with very low copper (JPI) that had low initial transition temperature below $-70^{\circ} \mathrm{C}$ showed low $\alpha$ values. Figure 7 shows the $\alpha$ value as a function of the initial Charpy transition temperature. It is seen that materials with low initial transition temperature show low $\alpha$ value, except for the JFL. This coincides with Refs. 12) and 13). The discrepancy in the JFL is not clear at this stage. Although influencing factors, i.e., copper content in steel, initial transition temperature and manufacturing method, on this relation should be studied carefully, this type of equation helps to estimate the shift of transition temperature from tensile test results.

For an assessment of irradiation damage at the upper shelf temperature range, a decrease percentage of USE has been used in a prediction formula. ${ }^{5)}$ Figure 8 shows the correlation between the decrease percentage of USE and $\sigma_{\mathrm{y}}$ increase. The USE values after irradiation was not determined for JPI, but the USE decrease was estimated to be less than $10 \%$ based on the load-time signals from instrumented Charpy impact tests. The relation between the USE decrease and $\sigma_{\mathrm{y}}$ increase is expressed by the following equation as is similar to the Eq. (3),

$$
\triangle \mathrm{USE}=\beta \times \Delta \sigma_{\mathrm{y}}
$$

\section{$\beta$ : coefficient, $0.17-0.55(\% / \mathrm{MPa})$ except for JPI}

The range of $\beta$ value, even except for the JPI, is broader than that of $\alpha$ value $(0.4-0.9)$ as was shown in Fig. 6. The correlation between USE decrease and $\sigma_{y}$ increase is somewhat weak when it is compared with the one between Charpy shift and $\sigma_{y}$ increase, although both coefficients have some ranges.

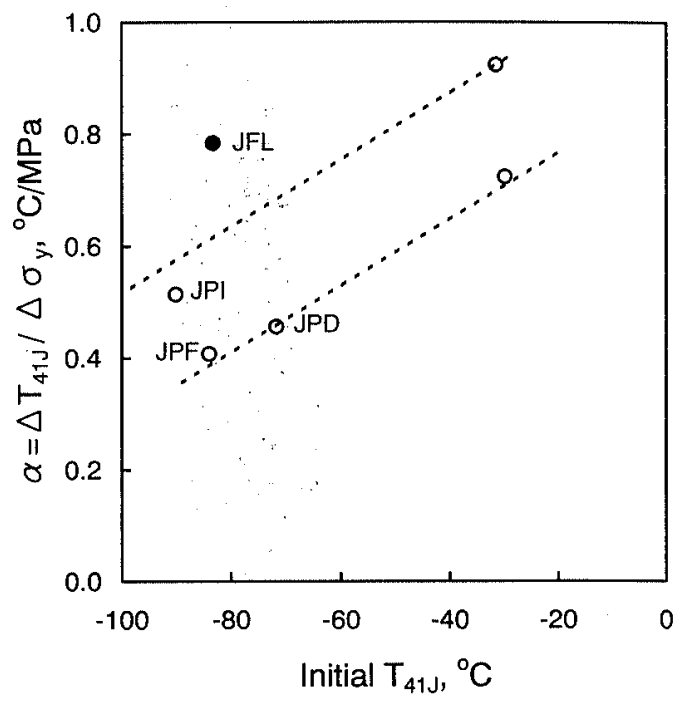

Fig. 7. Relationship between the coefficient $\alpha\left(=\Delta T_{41} / \Delta \sigma_{y}\right)$ and initial Charpy transition temperature. Low $\alpha$ values are seen for JPI with low $\mathrm{Cu}(0.01 \mathrm{wt} \%)$, and JPD and JPF which are the laboratory melted steels of $30 \mathrm{~mm}$ thick.

\subsection{Fracture Toughness Change in the Ductile-Brittle Transition Temperature Range}

Fracture toughness $\left(K_{\mathrm{IC}}\right)$ values in the ductile-brittle transition range were obtained before and after irradiation using PCCV and compact type specimens of JPI, $J P J$ and JRQ. A statistical analysis is required to evaluate the $K_{\mathrm{JC}}$ transition curve, because there is a large scatter of $K_{\mathrm{JC}}$ value in the transition temperature range. Additional tests were performed for only JRQ to establish the $K_{\mathrm{JC}}$ curve for unirradiated material more precisely. Figure 9 shows $K_{\mathrm{JC}}$ values from $\mathrm{PCCV}$ and compact specimens of JRQ before and after irradiation. ${ }^{14)}$ The mean $K_{\mathrm{JC}}$ curves were evaluated based on the master curve method including a statistical analysis, ${ }^{15)}$ assuming no change in the shape of $K_{\mathrm{JC}}$ curve after irradiation. The shift of the $K_{\mathrm{JC}}$ curve due to neutron irradiation was somewhat larger than that of the Charpy $41 \mathrm{~J}$ transition temperature. Figure 10 shows the temperature dependence of the $K_{\mathrm{JC}}$ values obtained from PCCV specimens of JPI and JPJ. The data bounding line for each condition

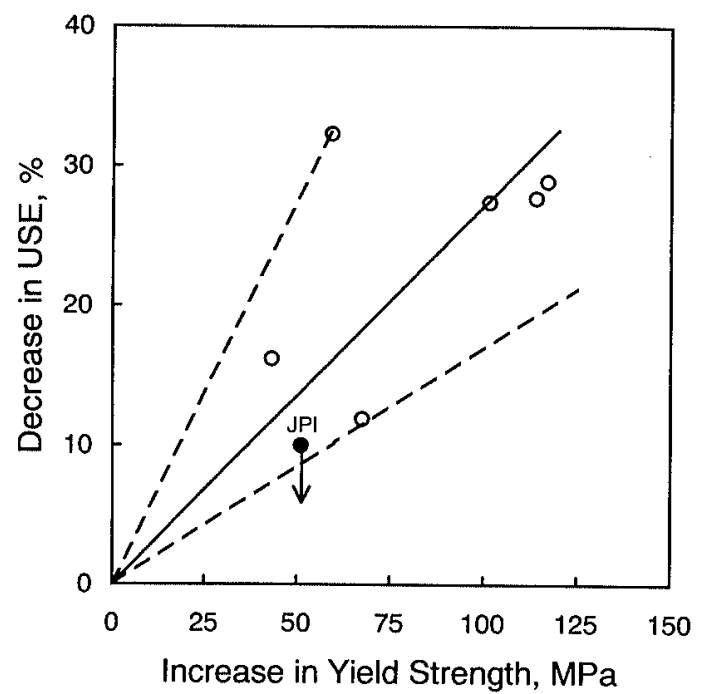

Fig. 8. Relationship between the decrease in USE and yield strength increase due to irradiation.

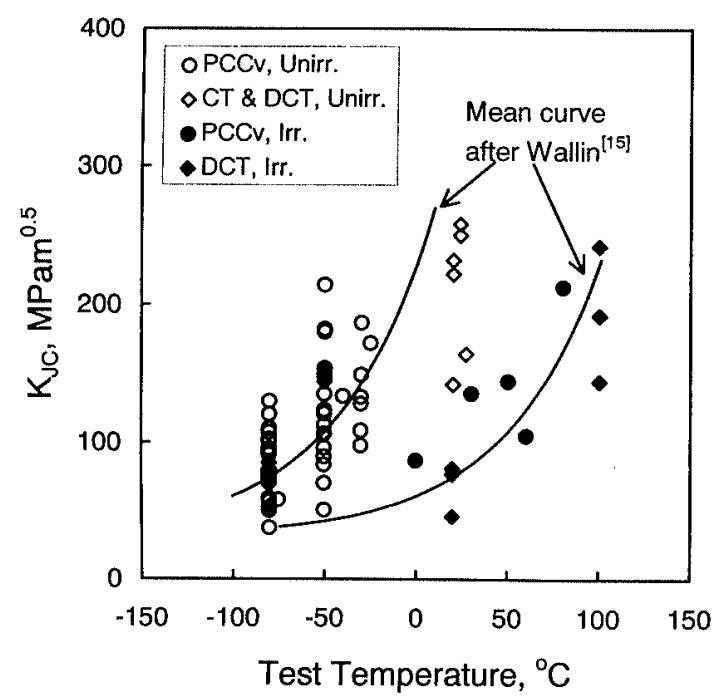

Fig. 9. Cleavage fracture toughness values of JRQ before and after irradiation. The mean curves for unirradiated and irradiated conditions based on Wallin's method ${ }^{15)}$ are also indicated. 


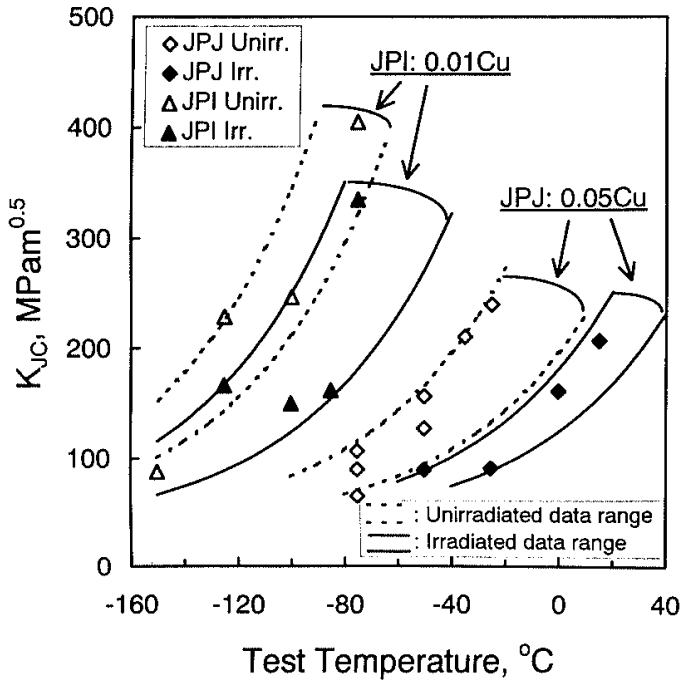

Fig. 10. Cleavage fracture toughness values of JPI and JPJ obtained from precracked Charpy type specimen before and after irradiation. The data bounding line for each condition is indicated.

is also indicated. Precise shifts of $K_{\mathrm{JC}}$ curves could not be determined for these materials, because the number of test data was too small to perform a statistical analysis to determine the $K_{\mathrm{JC}}$ curves. The bounding lines, however, show that the shift of $K_{\mathrm{JC}}$ curve for JPJ is larger than that for JPI. It is also found that the shift of $K_{\mathrm{JC}}$ curve for JPJ is smaller than that for JRQ shown in Fig. 9. The increases in $\sigma_{y}$ for these steels were the same tendency as the shift of $K_{\mathrm{JC}}$ curve. Therefore, the shift of $K_{\mathrm{IC}}$ curve is expected to be correlated with the increase in $\sigma_{y}$. In a code for integrity assessment of reactor pressure vessel, such as Section XI of ASME Boiler and Pressure Vessel code, ${ }^{16}$ ) the shift of fracture toughness transition curve is assumed to be equivalent to that of Charpy impact energy curve. In this respect, it is necessary to verify the relation between the shifts of transition curves for fracture toughness and Charpy impact energy. The number of irradiated specimens for fracture toughness test is normally limited by the space for irradiation. It is desirable to optimize testing and evaluation methods for the determination of fracture toughness transition curve after irradiation from a small number of specimen. The investigation on the optimization of fracture toughness measurement is now underway.

\subsection{Fracture Toughness Change in Upper Shelf Tem- perature Range}

The J-integral resistance $(J-\Delta a)$ curves of heavy section steels were evaluated at 100 and $200^{\circ} \mathrm{C}$ in the upper shelf temperature range based on the test results of two types of compact specimens. Figure 11 shows the relations of J-integral value and the amount of ductile crack extension, $\Delta a$, of JRQ at $200^{\circ} \mathrm{C}$ before and after irradiation. It is seen from the data for unirradiated specimens that there is no difference in the data between 0.5T-DCT and 1T-CT up to the ductile crack extension of $\sim 0.5 \mathrm{~mm}$. The amount of ductile crack extension almost corresponds to the length at which the $J_{\mathrm{Q}}$ is defined according to the ASTM standard. The crack

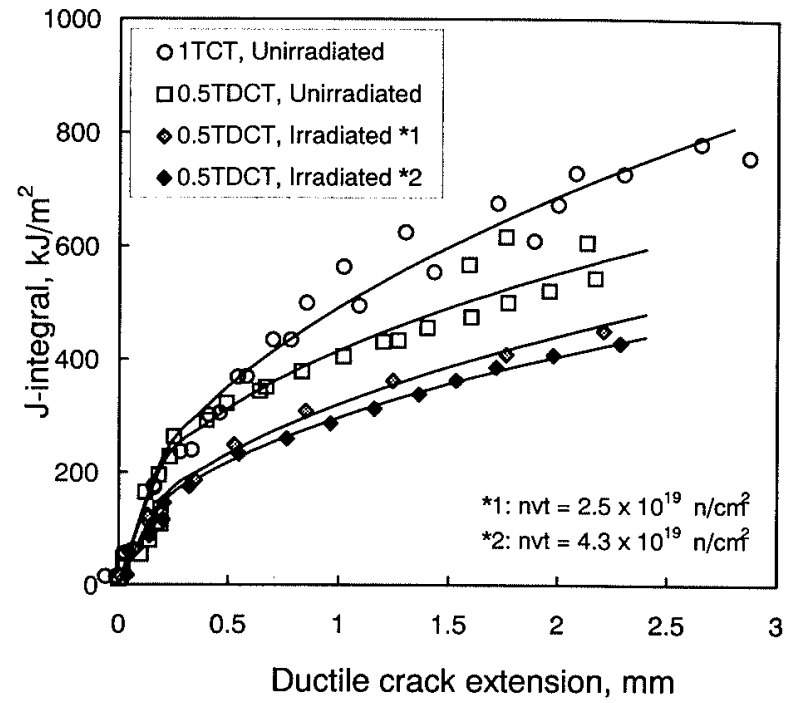

Fig. 11. Comparison of J-integral resistance curves of material $\mathrm{JRQ}$ at $200^{\circ} \mathrm{C}$ before and after irradiation.

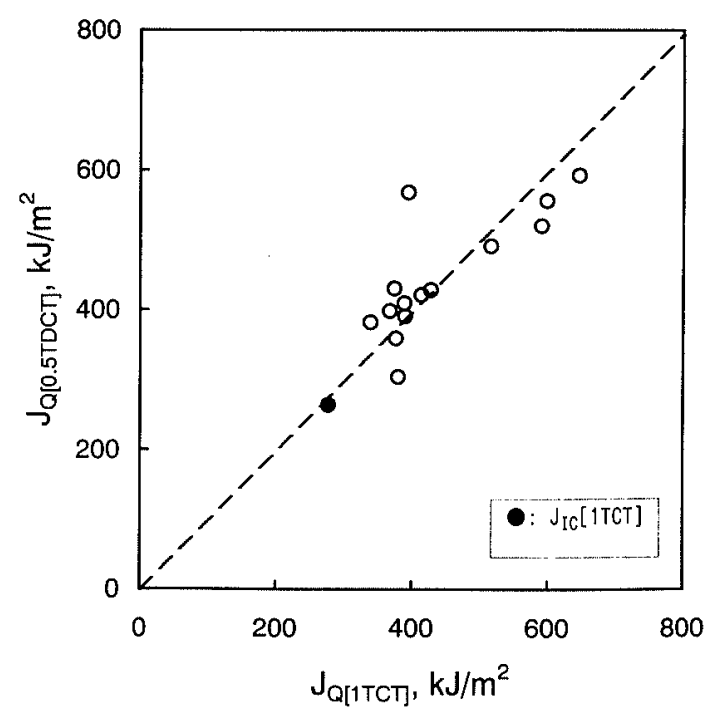

Fig. 12. Comparison of $J_{\mathrm{Q}}$ values obtained from $0.5 T$-DCT and 1T-CT.

initiation toughness $J_{\mathrm{IC}}$ is obtained from the validation of the $J_{\mathrm{Q}}$ by some requirements like specimen size. Figure 12 compares the $J_{\mathrm{Q}}$ values for unirradiated materials obtained from 0.5T-DCT with those from 1T-CT. Valid $J_{\mathrm{IC}}$ was obtained at only limited condition of low fracture toughness from 1T-CT, because the requirement on specimen size was not fulfilled at high toughness level for such a small specimen. $J_{\mathrm{Q}}$ values of both $0.5 \mathrm{~T}$ DCT and 1T-CT including $J_{\text {IC }}$ were, however, almost equivalent to each other, although the correlation factor $r$ is not so high $(r=0.76)$. On the other hand, the ductile crack growth resistance which corresponds to the slope of J-R curve, $d J / d a$, of 0.5T-DCT at the crack extension over $0.5 \mathrm{~mm}$ was slightly lower than that of $1 \mathrm{~T}-\mathrm{CT}$ as shown in Fig. 11. Therefore, the irradiation response on $J_{\mathrm{Q}}$ values is discussed below.

The $J-\Delta a$ data of irradiated specimens were lower than those of unirradiated specimens as shown in Fig. 11. Figure 13 shows the $J_{\mathrm{Q}}$ values for each material as a function of fast neutron fluence. The average $J_{\mathrm{Q}}$ values 


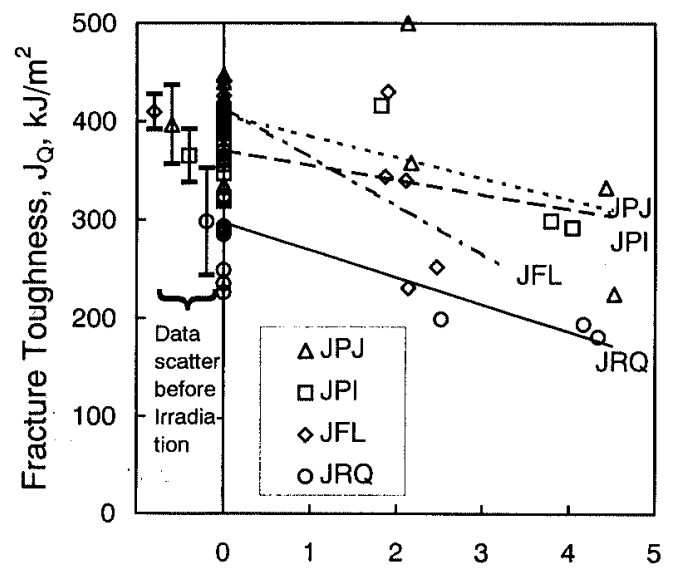

Fast Neutron Fluence, $\mathrm{n} / \mathrm{cm}^{2}, \mathrm{E}>1 \mathrm{MeV}$

Fig. 13. Change in fracture toughness, $J_{\mathrm{Q}}$, as a function of fast neutron fluence.

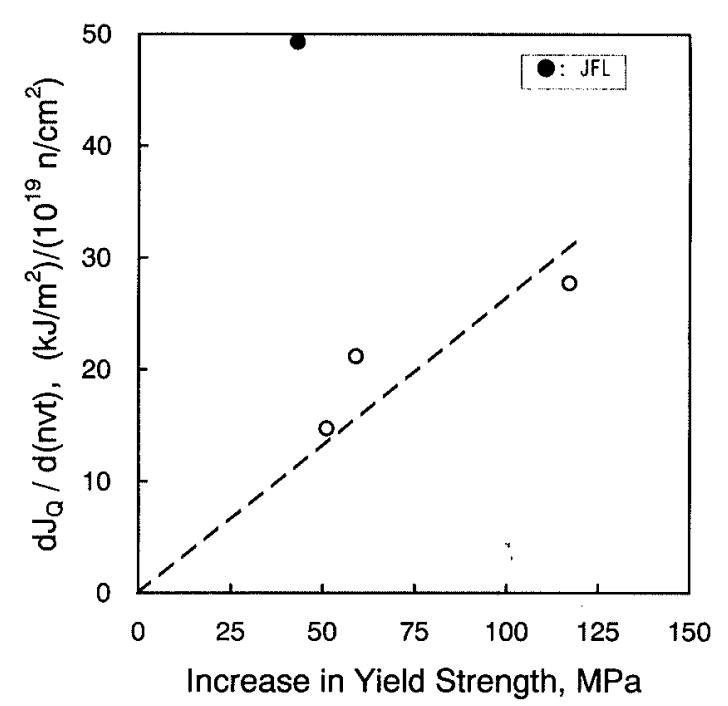

Fig. 14. Relationship between the decreasing slope of the regression line of fracture toughness shown in Fig. $13, d J_{\mathrm{Q}} / d(\mathrm{nvt})$, and the increase in yield strength due to irradiation.

with a standard deviation before irradiation are also shown in the figure. Valid $J_{\text {IC }}$ values were obtained only from JRQ steel, because other steels had very high toughness before and even after irradiation. The linear regression line for each material is also indicated in Fig. 13. Although the $J_{\mathrm{Q}}$ values after irradiation are scattered, it is found that neutron irradiation decreased the $J_{\mathrm{Q}}$ value. The decrease in $J_{\mathrm{Q}}$ value tends to be large for JFL, but lesser extent for JPI as clearly shown in the slope of the regression line.

In upper shelf temperature range, Charpy USE is used to evaluate the safety of reactor pressure vessel in some codes. For example, US 10 CFR part $50^{17)}$ stipulates that reactor vessel steel must maintain upper shelf energy of no less than $68 \mathrm{~J}$ throughout the life of the vessel. However, the integrity assessment of the vessel at the upper shelf temperature, i.e. around the operational temperature, requires practically the actual fracture toughness value, not Charpy absorbed energy value. Figure 14 shows the relation between the decreasing slope in fracture toughness, $d J_{\mathrm{Q}} / d(\mathrm{nvt})$, which

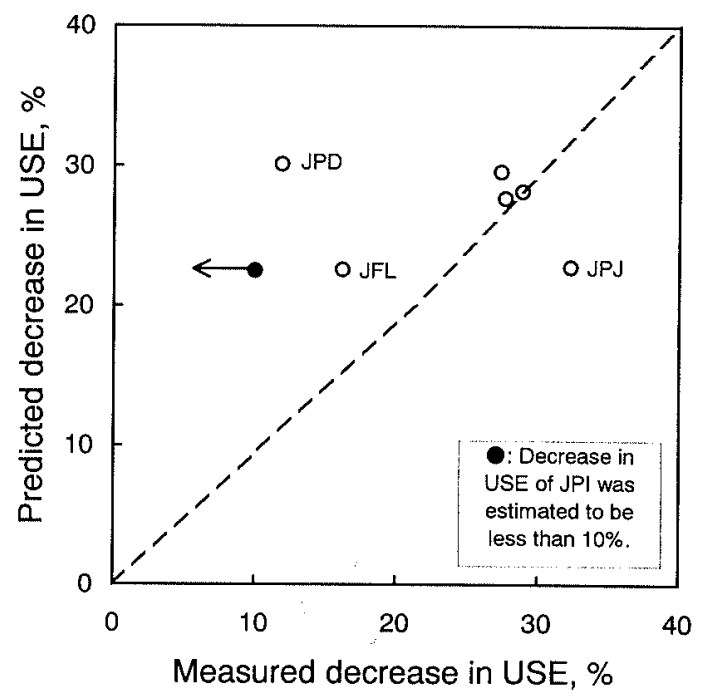

Fig. 15. Comparison of measured decrease of Charpy upper shelf energy and predicted one by the equation in the US NRC Regulatory Guide 1.99. ${ }^{5)}$

corresponds to the negative slope of the regression line in Fig. 13, and the increase in $\sigma_{y}$. This relation for three plate materials can be expressed by a dotted line as indicated in the figure. This correlation is better than the relationship between $\Delta$ USE and $\Delta \sigma_{y}$ shown in Fig. 9. This suggests the advantage of predicting fracture toughness rather than Charpy USE from the $\sigma_{y}$ increase for the integrity assessment of RPV. It is, however, necessary to make a further analysis on the effect of specimen size and the particular behavior of the JFL for the more reliable evaluation of the irradiation effect on fracture toughness.

From regulatory point of view, the decrease in USE should be evaluated as mentioned before. Figure 15 shows the relation between the predicted decrease in USE by the equation in the US NRC Regulatory Guide (R.G.) $1.99^{5}$ and the measured one. This figure indicates that the R.G. 1.99 overestimates for JPI, JFL and JPD, which have either low $\mathrm{Cu}$ or low $\mathrm{Ni}$ contents. On the other hand, it underestimates for JPJ by $10 \%$, which has also low content of $\mathrm{Cu}$. Although the prediction equation in the R.G. 1.99 has been formulated with $\mathrm{Cu}$ content above $0.10 \mathrm{wt} . \%$ for base metal and neutron fluence, the decrease in USE may be varied with other variables. The correlation between the decrease in fracture toughness and irradiation hardening, therefore, is expected to be more useful for the integrity assessment of RPV than that between the decrease in USE and irradiation hardening.

\section{Conclusions}

As a part of the IAEA Coordinated Research Program, irradiation hardening and embrittlement of seven kinds of RPV steels containing different contents of $\mathrm{Cu}$ and $\mathrm{Ni}$ were investigated. Some mechanical property changes due to neutron irradiation were examined by conducting tensile, hardness, Charpy impact and fracture toughness tests. Thereby the responses of different mechanical properties were correlated. The increase in yield strength from tensile tests, which increases with 
both $\mathrm{Cu}$ and $\mathrm{Ni}$ contents, was mainly used as a baseline of the relationship. The conclusions obtained are:

(1) The increase in yield strength can be correlated well with hardness increase and Charpy transition temperature shift.

(2) The shift of transition temperature in fracture toughness is somewhat larger than that in Charpy transition temperature.

(3) In the upper shelf temperature range, the decrease in fracture toughness is correlated well with the increase in yield strength.

(4) The decrease in upper shelf energy is not correlated well with the increase in yield strength.

It is noted that the optimization of the method to evaluate the fracture toughness from a small number of irradiated specimen is necessary.

\section{Acknowledgments}

This work was done in the framework of the phase III program of IAEA coordinated research on optimizing of reactor pressure vessel surveillance program and their analysis. The authors wish to thank Mr. A. Kohsaka, Dr. K. Shibata and, Dr. S. Ueda, JAERI for their helpful discussion and suggestions. They would also like to thank Messrs. T. Watanabe and R. Kato of JAERI for their technical supports. Thanks are also due to many staffs in JMTR Project and Research Hot Laboratory for performing material irradiation and conducting the post irradiation tests, respectively.

In addition, the authors appreciate that this work was supported by the members of CRP Sub-Committee (Chairman: Professor Emeritus of The University of Tokyo, Y. Ando) of the Atomic Energy Research Committee of the Japan Welding Engineering Society.

\section{REFERENCES}

1) IAEA: Co-ordinated Research Programme on Irradiation Embrittlement of Pressure Vessel Steels, IAEA-176, Vienna, (1975).

2) IAEA: Analysis of the Behaviour of Advanced Pressure Vessel Steels under Neutron Irradiation, IAEA Technical Report Series No. 265, Vienna, (1986).

3) L. E. Steele, L. M. Davies, T. Ingham and M. Brumovsky: Effects of Radiation on Materials, ASTM STP 870, (1985), 863.

4) K. Onizawa, M. Suzuki and S. Ueda: JAERI Contribution for the IAEA Coordinated Research Program Phase III (CRP-3) on Optimizing of Reactor Pressure Vessel Surveillance Programmes and their Analysis, JAERI-M 93-201, October, (1993).

5) Revision 2 of US NRC Regulatory Guide 1.99, Radiation Damage to Reactor Vessel Materials, US Nuclear Regulatory Commission, (1988).

6) R. E. Stoller: Effect of Radiation on Materials: 17th Int. Symp., ASTM STP 1270, (1996), 25.

7) CRP Sub-Committee: Manufacturing History and Mechanical Properties of Japanese Materials Provided for The International Atomic Agency, Japan Welding Engineering Society, Oct. (1986).

8) ASTM E399-83: Standard Test Method for Plane-Strain Fracture Toughness, ASTM Standards, Vol. 03.01.

9) W. Oldfield: ASTM Stand. New', 3 (1975), No. 11, 24.

10) ASTM E813-89: Standard Test Method for $J_{\text {IC }}$, a Measure of Fracture Toughness, ASTM Standards, Vol. 03.01.

11) G. R. Odette and G. E. Lucas: The Effect of Nickel on Irradiation Hardening of Pressure Vessel Steels, Effects of Radiation on Materials, ASTM STP 1046, (1990), 323.

12) G. R. Odette, P. M. Lombrozo and R. A. Wullaert: Effects of Radiation on Materials, ASTM STP 870, (1985), 840.

13) M. Suzuki, K. Onizawa and M. Kizaki: Effect of Radiation on Materials: 17th Int. Symp., ASTM STP 1270, (1996), 351.

14) K. Onizawa and M. Suzuki: Proc. of the IAEA Specialists' Meeting on Irradiation Embrittlement and Mitigation, Finland, October 23-26, IAEA IWG-LMNPP-95/5, Vienna, (1995).

15) K. Wallin: Int. J. Pressure Vessel Piping, 55 (1993), 61.

16) Section XI of ASME Boiler and Pressure Vessel Code, Appendix A, Analysis of Flaws, American Society of Mechanical Engineers, New York, (1986).

17) Title 10, Code of Federal Regulations, Part 50, US Government Printing Office, Washington DC, (1987). 